\title{
ANALISIS SIFAT MEKANIK PENGELASAN BIMETAL PLAT BAJA KARBON RENDAH DAN STAINLESS STEEL DENGAN LAS GTAW
}

\author{
Sarjiyana, Lisa Agustriyana, Suyanta \\ Jurusan Teknik Mesin, Politeknik Negeri Malang \\ Email: sarjiyana@polinema.ac.id \\ (Artikel diterima: Februari 2020, direvisi: April 2020, diterima untuk terbit: Juli 2020)
}

\begin{abstract}
Abstrak - Bahan baja tahan karat (stainless steel) banyak digunakan dalam industri rumah tangga maupun industri militer, dan juga dalam industri nuklir. Bahan baja dibagi menjadi lima tipe yaitu austenite, ferite, martensite, duplex dan precipitation hardening. Baja tahan karat feritik merupakan alternatif yang menarik dalam produksi kendaraan karena sifat ketahanan terhadap laju korosi. Logam yang tidak sejenis mempunyai karakteristik yang berbeda satu dengan lainnya, sehingga proses pengelasan logam yang tidak sejenis memerlukan beberapa teknik tertentu. Tujuan penelitian ini yaitu mengetahui kekuatan tarik lasan pada pengelasan bimetal antara plat baja karbon rendah dengan plat stainless steel dan mengetahui kekerasan lasan pada pengelasan bimetal antara plat baja karbon rendah dengan plat stainless steel menggunakan las GTAW. Metode Penelitian yang digunakan: penelitian ini merupakan bagian dari pengujian bahan teknik yang dilakukan dengan metoda destructive test dengan katagori pengembangan IPTEK bidang Teknik Mesin. Terjadi trend peningkatan kekuatan tarik, kekuatan yield dan kekerasan dari pengelasan bimetal plat baja karbon rendah dan plat stainless steel menggunakan las GTAW, bahwa semakin besar ampere pengelasan akan meningkatkan kekuatan tarik, kekuatan yield dan kekerasan. Kekuatan tarik tertinggi sebesar $41,18 \mathrm{Kg} / \mathrm{mm} 2$ dan kekuatan yield tertinggi sebesar $41,16 \mathrm{Kgf} / \mathrm{mm} 2$ pada 60 ampere dan kekerasan tertinggi sebesar 571,01 BHN pada 55 ampere dengan range ampere sesuai dari tabel penggunaan 45 - 65 ampere. Pada daerah HAZ jika dibandingkan terhadap material induk, kekerasan daerah HAZ kekerasannya lebih tinggi dari material induk dan lebih rendah dari filler las.
\end{abstract}

Kata kunci: Bimetal, GTAW, Kekuatan Tarik, Kekerasan

\section{Pendahuluan}

Pengelasan bimetal merupakan proses penyambungan dua jenis logam yang berbeda dengan pengelasan. Pengelasan logam yang tidak sejenis mempunyai karakteristik yang berbeda satu dengan lainnya, sehingga proses pengelasan logam yang tidak sejenis memerlukan beberapa teknik pengelasan tersendiri, contohnya dalam pemilihan logam yang akan disambung harus tepat, pemilihan elektroda yang digunakan harus sesuai, pengaturan ampere yang tepat. Oleh karena itu dibutuhkan cara supaya pengelasan bimetal dapat diterima dan akhirnya dapat diterapkan dengan baik sesuai dengan yang diinginkan.

Dari itulah pentingnya penelitian terkait dengan pengelasan khususnya pengelasan untuk jenis bahan yang berbeda dengan dengan menggunakan pengelasan Gas Tungten Arc Welding (GTAW)

1) Penelitian terdahulu untuk bimetal yaitu

Analisis Struktur Kristal Hasil Las Friction-Stir

Welding pada Retreating Side Bimetal Disimilar

Aa6061-Cu dengan Teknik Difraksi

Masalah yang dirumuskan sebagai pengukuran perubahan kekuatan yield, kekuatan tarik dan kekerasan pada pengelasan bimetal plat baja karbon rendah dan stainless steel dengan menggunakan las GTAW

Tujuan penelitian mengetahui kekuatan tarik lasan dan kekerasan lasan, HAZ pada pengelasan bimetal antara plat baja karbon rendah dengan plat stainless steel menggunakan las GTAW.

\section{Tinjauan Pustaka}

\section{A. 2.1 Pengertian Sambungan}

Setiap konstruksi mesin terdiri dari beberapa bagian atau komponen. yang satu dan yang lainnya dapat dihubungkan dan membentuk suatu konstruksi mesin yang di rancang. Salah satu cara dalam menyatukan komponenkomponen tersebut adalah dengan cara memberikan sambungan. Sambungan adalah hasil penyatuan beberapa bagian atau konstruksi dengan menggunakan suatu cara tertentu.

Macam-macam sambungan

a. Sambungan Tetap, yaitu sambungan yang hanya dapat dilepas dengan cara merusaknya. Contohnya : sambungan keling dan sambungan las.

b. Sambungan tidak tetap, yaitu sambungan yang dapat kita lepas dan dibongkar tanpa merusak sesuatu. Contohnya sambungan pasak, sambungan pena, dan sambungan ulir.

\section{B. Pengelasan GTAW}

Pengertian pengelasan GTAW adalah sebuah proses pengelasan busur listrik yang menggunakan elektroda yang tidak ikut mencair. Pada pengelasan GTAW ini elektroda atau tungsten ini hanya berfungsi sebagai penghasil busur listrik saat bersentuhan dengan benda kerja, sedangkan untuk logam pengisi adalah filler rod. Pengelasan GTAW ini juga sering disebut dengan Las Argon, hal tersebut dikarenakan gas pelindung yang digunakan adalah gas Argon.

Las GTAW ini juga disebut dengan Las TIG yang mempunyai kepanjangan Tungsten Inert Gas, perbedaan ini hanya penyebutannya saja. Kalau GTAW itu lebih sering untuk istilah Amerika sedangkan TIG adalah untuk daerah 
Eropa. Fungsi Las GTAW ini biasanya digunakan untuk melakukan pengelasan Aluminium atau stainless steel yang memang banyak membutuhkan perlakuan khusus.

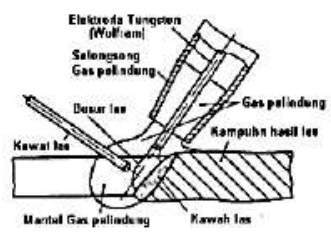

Gambar 2.1. Proses las GTAW.

\section{Mengenal Bahan Pelat atau Plat}

Pelat atau plat terdiri dari berbagai jenis bahan. Secara garis besar bahan pelat ini dikelompokkan menjadi dua bagian besar yang memiliki sifat berbeda-beda yakni: bahan pelat logam ferro dan pelat logam non ferro. Bahan pelat logam ferro diantaranya adalah pelat baja lembaran. Bahan pelat dari logam non ferro diantaranya bahan pelat alumanium, tembaga, dan kuningan. Sifat-sifat bahan ferro dan non ferro sangat mempengaruhi pembentukan maupun finishing yang akan dilakukan pada bahan pelat tersebut. Secara umum bahan-bahan logam mempunyai sifat fisik dan sifat kimiawi terhadap efek kualitas pengerjaannya.

\section{Pengelasan Baja Paduan Rendah}

Yang termasuk baja paduan rendah adalah baja-baja yang mengandung unsur paduan dengan jumlah kurang dari $5 \%$ dan mengandung $0,25-0,5 \% \mathrm{C}$.

Keberhasilan pengelasan baja paduan rendah tidak hanya tergantung pada jenis proses dan pemilihan electrode, tetapi juga ada factor lain yang berpengaruh dan harus diperhatikan seperti:

- Temperatur pemanasan awal (Preheat) dan temperatur antar lapisan (interpass)

- Kandungan hydrogen dijaga rendah khususnya dalam kasus preheat dibawah temperature $205^{\circ}$.

- $\quad$ Persyaratan pemanasan pada akhir pengelasan (PWHT).

\section{E. Pengelasan Baja Tahan Karat (Stainless Steel)}

Pemilihan electrode/filler dalam pengelasan baja tahan karat didasarkan pada kemiripan komposisi kimia dari logam induk dengan electrode/filler. Jadi sebisa mungkin electrode/filler dan logam induk sejenis. Pertimbangan lainnya yang cukup penting adalah yang berkaitan dengan sifat ketahanan korosi dan ketahanan terhadap timbulnya retak. Pada dasarnya baja tahan karat ada 3 jenis yaitu baja tahan karat Austenitik, Feritik, dan Martensitik seperti pada tabel

Tabel 2.1 Tipe dan komposisi baja tahan karat (Stainless Steel)

\begin{tabular}{|c|c|c|c|}
\hline Element & Ferritic & Martensitic & Austenitic \\
\hline Carbon & $0.08-0.20 \%$ & $0.15-1.2 \%$ & $0.03-0.25$ \\
\hline Manganese & $1-1.5 \%$ & $1 \%$ & $2 \%(5.5-10 \%)$ \\
\hline Silicon & $1 \%$ & $1 \%$ & $1-2 \%(0 \%)$ \\
\hline Chromium & $11-27 \%$ & $11.5-18 \%$ & $16-26 \%$ \\
\hline Nickel & & & $3.5-22 \%$ \\
\hline $\begin{array}{c}\text { Phosphorus and } \\
\text { Sulfur }\end{array}$ & & & Normal ( $0 \%)$ \\
\hline Molydenum & & & Some cases \\
\hline Titanium & & & Some cases \\
\hline
\end{tabular}

\section{F. Pengelasan Baja Tahan Karat Austenitic}

Baja tahan karat austenitic mempunyai sifat lebih mudah dilas dibanding baja tahan karat feritik dan martensitik, karena pada baja austenitic ini tidak terjadi perubahan phase akibat temperature pengelasan. Sambungan las mempunyai sifat liat (Ductile). Baja tahan karat tipe 303 dan 303 SE mengandung sulfur dan selenium untuk memudahkan dimesin, tetapi untuk pengelasan mudah terjadi "Hot Short Cracking “. Untuk tipe lain seperti tipe 302, 304, dan 304L mudah dilakukan pengelasan dan untuk menghindari terjadinya karbida krom pada batas butir pengelasan dapat dilakukan dengan kawat las Grade "L" seperti 304L, 316L,317L. Kawat las untuk pengelasan baja tahan karat jenis austenitrik seperti yang di sarankan pada tabel berikut:

Tabel 2.2 Kawat las yang disarankan untuk pengelasan baja tahan karat austenitic

\begin{tabular}{|c|c|}
\hline $\begin{array}{c}\text { Bahan dasar/Logam } \\
\text { induk AISI }\end{array}$ & Kawat Las \\
\hline 302,304 & 308 \\
\hline $304 \mathrm{~L}$ & $308 \mathrm{~L}, 347$ \\
\hline $303,303 \mathrm{Sc}$ & 312 \\
\hline 310 & 310 \\
\hline 316 & 316 \\
\hline $316 \mathrm{~L}$ & $318,316 \mathrm{~L}$ \\
\hline 317 & 317 \\
\hline $318,316(\mathrm{Cb})$ & 318 \\
\hline 312 & 347 \\
\hline 347 & 347 \\
\hline 348 & 347 \\
\hline
\end{tabular}

\section{G. Pengelasan Baja Tahan Karat Feritik}

Baja tahan karat jenis ini mempunyai kandungan 12 $30 \%$ chrom, sehingga kemampuan untuk dilas lebih rendah dibandingkan dengan baja tahan karat austenitic. Dikarenakan mempunyai fasa feritik, maka baja tahan karat jenis ini jika dilas sebagian struktur mikronya akan berubah menjadi martensit didaerah HAZ (Heat Affected Zone)/daerah yang terpengaruh oleh panas las.

Untuk menghindari terjadinya martensit tanpa annealing, maka dapat dipilih bahan yang kuat untuk membentuk ferit seperti $\mathrm{Ti}, \mathrm{Al}$ dan $\mathrm{Wb}$, atau pengelasan menggunakan pemanasan awal atau Preheat. Tabel 2.3 dan 2.4 adalah pemilihan kawat las (filler) yang disarankan dan pemanasan awal untuk pengelasan baja tahan karat jenis feritik.

Tabel 2.3 Kawat las yang disarankan untuk pengelasan baja tahan karat Feritik

\begin{tabular}{|c|c|}
\hline $\begin{array}{c}\text { Bahan dasar/Logam induk } \\
\text { AISI }\end{array}$ & Kawat Las \\
\hline 405 & $405(\mathrm{Cb}), 430,308,309,310$ \\
\hline 430 & $430,308,309,310$ \\
\hline $430 \mathrm{~F}$ & $430,308,309,310$ \\
\hline 442 & $442,308,309,310$ \\
\hline 446 & $446,308,309,310$ \\
\hline
\end{tabular}


Tabel 2.4 Temperatur pemanasan awal dan perlakuan panas yang disarankan untuk pengelasan baja tahan karat feritik

\begin{tabular}{|c|c|l|}
\hline $\begin{array}{c}\text { Bahan dasar/Logam } \\
\text { induk AISI }\end{array}$ & $\begin{array}{c}\text { Temperatur } \\
\text { pemanasan awal }^{\circ}{ }^{\circ} \text { C }\end{array}$ & $\begin{array}{c}\text { Temperatur } \\
\text { Pemanasan lanjut dan } \\
\text { pendinginan }\end{array}{ }^{\circ} \mathbf{C}$ \\
\hline 405 & $66-149$ & $\begin{array}{l}648-760 \text { dinginkan } \\
\text { diudara }\end{array}$ \\
\hline 409 & $66-149$ & $\begin{array}{l}648-760 \text { dinginkan } \\
\text { diudara }\end{array}$ \\
\hline 430 & $66-149$ & $\begin{array}{l}760-842 \text { dinginkan } \\
\text { diudara }\end{array}$ \\
\hline 442 & $149-260$ & $\begin{array}{l}787-898 \text { segera } \\
\text { didinginkan }\end{array}$ \\
\hline 446 & $149-260$ & \multicolumn{1}{|c}{-} \\
\hline
\end{tabular}

\section{H. Pengelasan Baja Tahan Karat Martensitik}

Baja tahan karat martensitik lebih sulit dilas dibanding dengan baja tahan karat feritik, karena adanya perubahan fasa dari austenite menjadi martensit pada saat pendinginan setelah pengelasan, sehingga pengelasan membutuhkan caracara khusus untuk mengendalikan supaya tidak retak.

Cara yang efektif untuk mencegah keretakan las adalah dengan pemanasan awal dan mengontrol temperatur pengelasan interpass, dan pemanasan lanjutan sesuai kadar karbon, sebagi pedoman adalah :

1. Karbon $0,10 \%$ umumnya tidak perlu pemanasan awal dan lanjutan

2. Karbon $0,10-0,20 \%$ pemanasan awal $260^{\circ} \mathrm{C}$ dan pengelasan interpas, pendinginan perlahan.

3. Karbon $0,20-0.50 \%$ Pemanasan awal $260^{\circ} \mathrm{C}$ dan pengelasan interpas, dan annealing setelah pengelasan

4. Karbon diatas $0,50 \%$ Pemanasan awal $260^{\circ} \mathrm{C}$ dan pengelasan interpas dengan Heat input yang tinggi dan dilanjut dengan annealing setelah pengelasan (langsung tidak menunggu dingin).

Jika lasan akan dikeraskan (hardened), maka tidak perlu di annealing, kawat las dan temperature annealing yang disarankan dapat dilihat seperti tabel berikut:

Tabel 2.5 Macam-macam kawat las/filler yang dapat dipakai untuk baja tahan karat Martensitik

\begin{tabular}{|c|c|}
\hline Bahan dasar /Logam induk AISI & Kawat Las \\
\hline $403,410,416,416 \mathrm{SE}$ & 410 \\
\hline 403,410 & $308,309,310$ \\
\hline $416,416 \mathrm{SE}$ & $308,309,312$ \\
\hline 420 & 420 \\
\hline 431 & 420 \\
\hline 431 & $308,309,310$ \\
\hline
\end{tabular}

\section{METODE}

Jenis metode penelitian yang dilakukan adalah penelitian eksperimental. Penelitian dilakukan di laboratorium Perlakuan Bahan Jurusan Teknik Mesin Politeknik Negeri Malang. dan Laboratorium Pengijian Bahan, Teknik Mesin, Fakultas Teknik, Universitas Brawijaya.

Skema rancangan penelitian seperti terlihat pada gambar 3.2 sebagai berikut:

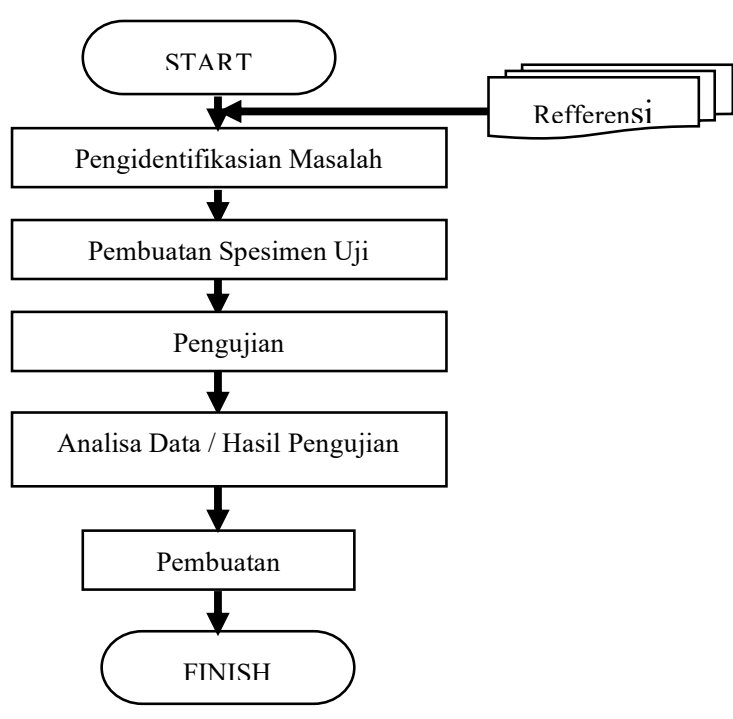

Gambar 3.2 Rancangan Penelitian

\section{A. Prosedur penelitian}

\section{Pemilihan Bahan sampel}

Bahan yang digunakan dalam penelitian ini yaitu plat baja karbon rendah tebal $3 \mathrm{~mm}$ dan plat stainless steel tebal 3 mm yang umum ada di pasaran sekitar Malang raya. Bahan spesimen plat baja karbon rendah ukuran 2400x1200x3 dan plat stainless steel ferritic ukuran $2400 \times 1200 \times 3 \mathrm{~mm}$ di potong menjadi $150 \times 25 \times 3 \mathrm{~mm}$.

\section{Pembuatan sampel}

Bahan yang sudah dipotong selanjutnya dilakukan proses pengelasan antara plat baja karbon rendah dengan plat stainless steel. Pengelasan dilakukan dengan mengatur perubahan Ampere las. Hasil pengelasan bimetal dari plat baja karbon rendah dan stainles steel feritic, permukaan dibersihkan (digerinda) dan dipotong menjadi bahan uji tarik ASTM E-8M dengan ukuran menjadi 250x20x3mm

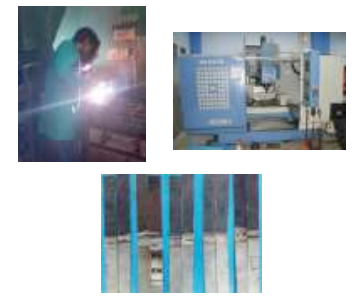

Gambar 3.3 Pembuatan sampel

\section{Pengujian sampel}

Bahan spesimen setelah dilakukan pengelasan dan pemesinan, selanjutnya dilakukan pengujian sifat mekanik material khususnya pengujian Tarik dan pengujian kekerasan, baik untuk bahan spesimen sebelum dilakukan pengelasan (data bahan baku) dan pengujian pada sambungan hasil lasan. Pengujian dilakukan pada daerah HAZ pada bahan plat baja karbon rendah, HAZ pada bahan plat baja stainless steel ferritic dan sambungan lasan. Data hasil pengujian Tarik pengujian kekerasan, pada pengujian Tarik data yang dikumpulkan adalah tegangan yield, tegangan ultimate dan kekerasan. 


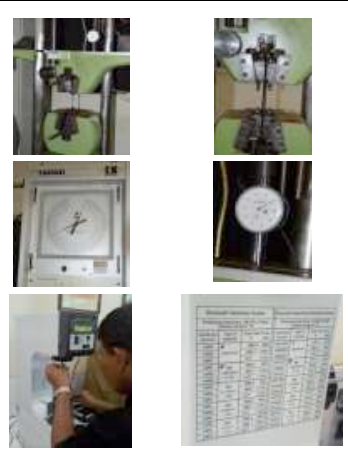

Gambar 3.4 Pengujian sampel

\section{Hasil dan Pembahasan}

\section{A. Hasil}

Setelah dilakukan proses pembuatan sample, meliputi pemotongan, pengelasan plat bimetal antara plat baja karbon rendah dan stainless steel dengan pengaturan ampere $45 \mathrm{~A}$, $50 \mathrm{~A}, 55 \mathrm{~A}, 60 \mathrm{~A}, 65 \mathrm{~A}$ selanjutnya dilakukan proses pemesinan untuk pembuatan sampel.

Selanjutnya hasil karakterisasi pada cuplikan (sampling) bahan lasan bimetal baja karbon rendah stainless steel dilakukan pengujian tarik pada pusat lasan (Welding Zone). Pengukuran kekerasan pada posisi logam dasar (Base Metal Welding), daerah terpengaruh panas plat baja karbon rendah (HAZ Low Carbon Steel), daerah terpengaruh panas plat baja stainless steel (HAZ Stainless Steel) dan daerah pusat lasan (Welding Zone).

Dari pengumpulan data hasil pengujian maka dapatlah dihitung harga rata-rata pengujian sebagai berikut:

Tabel 4.6 Perhitungan rata hasil pengujian tarik plat baja karbon rendah dan stainless steel
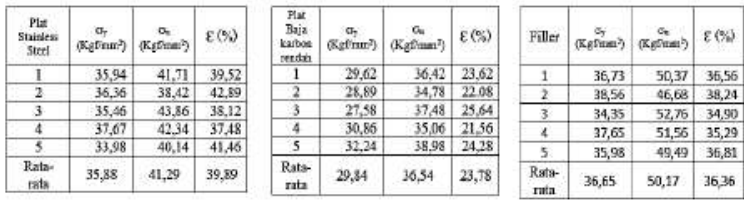

Tabel 4.7 Perhitungan rata-rata hasil pengujian tarik

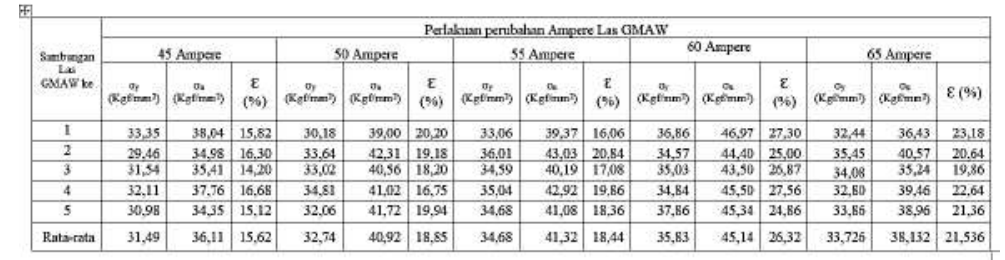

Tabel 4.8 Perhitungan rata-rata kekarasan plat low carbon steel dan stainless steel

\begin{tabular}{|c|c|c|}
\hline Bahan & $\begin{array}{c}\text { Plat Baja Karbon } \\
\text { Rendah (HR15N) }\end{array}$ & $\begin{array}{c}\text { Plat Stainless Steel } \\
\text { (HR15N) }\end{array}$ \\
\hline 1 & 50,60 & 51,80 \\
\hline 2 & 50,54 & 51,96 \\
\hline 3 & 50,63 & 51,76 \\
\hline 4 & 50.46 & 51,72 \\
\hline 5 & 50,65 & 51,82 \\
\hline $\begin{array}{c}\text { Rata- } \\
\text { rata }\end{array}$ & $\mathbf{5 0 , 5 8}$ & $\mathbf{5 1 , 8 1}$ \\
\hline
\end{tabular}

Tabel 4.9 Perhitungan rata-rata hasil pengujian kekerasan

\begin{tabular}{|c|c|c|c|c|c|c|c|c|c|c|c|c|c|c|}
\hline \multicolumn{15}{|c|}{ Peathiluan persubahan } \\
\hline \multicolumn{3}{|c|}{ 50 Ampere } & \multicolumn{3}{|c|}{60 Ampere } & \multicolumn{3}{|c|}{70 Ampere } & \multicolumn{3}{|c|}{ BOAmpae } & \multicolumn{3}{|c|}{ 90 Ampere } \\
\hline 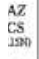 & $\begin{array}{c}\text { HAZ } \\
\text { SSI } \\
\text { arkisg }\end{array}$ & 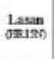 & $\begin{array}{c}\text { HAZ } \\
\text { LCS } \\
\text { DLIs: }\end{array}$ & $\begin{array}{c}\mathrm{HAZ} \\
\text { SST } \\
\text { oxises }\end{array}$ & 售 & $\begin{array}{c}\text { HAZ } \\
\text { LCS } \\
\text { acksos }\end{array}$ & $\begin{array}{c}\text { HAZ } \\
\text { SST } \\
\text { ooxison }\end{array}$ & 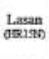 & $\begin{array}{l}\text { HAZ } \\
\text { LCS } \\
\text { QCELISD }\end{array}$ & $\begin{array}{c}\mathrm{HAZ} \\
\text { SST } \\
\text { arisisg }\end{array}$ & 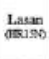 & $\begin{array}{l}\text { HAZ } \\
\text { LCS } \\
\text { aRLISN }\end{array}$ & $\begin{array}{c}\mathrm{HAZ} \\
\text { SST } \\
\text { ankisso }\end{array}$ & 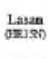 \\
\hline 2,00 & 61,40 & 53,00 & 6,00 & 57,00 & 89,50 & 9,40 & 62,50 & 78,50 & 12,70 & 58,20 & 56,00 & 4,40 & 63,10 & 59,70 \\
\hline 4.10 & 60,40 & 53,40 & 5,20 & 57.70 & 88,30 & 7,30 & 60,60 & 79.35 & 10,40 & 60,10 & 56.50 & 3.60 & 66,70 & 58,80 \\
\hline 3,00 & 60,80 & 53,00 & 6,00 & 57,10 & 86,40 & 8,50 & 61,30 & 79,30 & 11,50 & 59,20 & 57,10 & 3,80 & 64,80 & 59.60 \\
\hline 2,0 & 61,20 & 53,30 & 5.70 & 66,90 & 84,60 & 7,80 & 60,90 & 76,60 & 1090 & 58,90 & 56,20 & 3,20 & 65,10 & 58,90 \\
\hline 3,10 & $\infty, \infty 0$ & $54, \infty 0$ & 0,10 & 58,10 & 85.70 & 9.90 & 62,20 & 77,90 & 11,20 & 59,80 & 56,10 & 4,20 & 65,60 & 59,20 \\
\hline 3,10 & 60,83 & 53.00 & 5,92 & 57.36 & 86.90 & 8,40 & 61.50 & 78,33 & 11.34 & 50,24 & 56.50 & 3.84 & 65,06 & 99.24 \\
\hline
\end{tabular}

\section{B. Pembahasan}

Untuk mendukung interpretasi hasil perhitungan diatas, maka perlu dibuat dibuat grafik

GRAFIK PERUBAHAN TEGANGAN

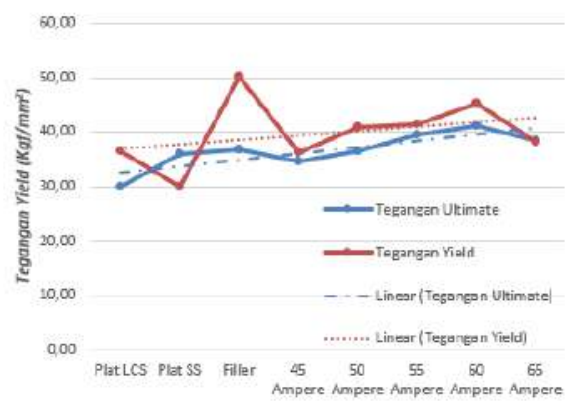

Gambar 4.5 Grafik tegangan tarik dan Ampere Las

Ditinjau terhadap perubahan tegangan yield, gambar 4.5 menunjukkan terjadinya trend kenaikan tegangan yield dari perubahan pengaturan ampere las pada pengelasan Gas Tungsten Arc Welding (GTAW) dari 45 ampere sampai 65 ampere. Kenaikan tertinggi, tegangan yield terjadi pada penggunaan ampere 60 ampere sebesar 35,83 Kgf $/ \mathrm{mm}^{2}$, jika dibandingkan dengan material dasar untuk plat baja karbon rendah mengalami kenaikan kekuatan yield sebesar 20,09\% dan plat stainless steel mengalami penurunan keuatan yield sebesar $23,53 \%$, serta dibandingkan dengan bahan filler mengalami penurunan sebesar 2,24\%. Disini dapat diketahui bahwa kekuatan yield pada lasan bimetal, berada diatas kekuatan yield plat baja karbon rendah dan plat stainless steel serta berada dibawah kekuatan yield bahan filler.

Ditinjau terhadap perubahan tegangan ultimate, gambar 4.5 menunjukkan terjadinya trend kenaikan tegangan yield dari perubahan pengaturan ampere las pada pengelasan Gas Tungsten Arc Welding (GTAW) dari 45 ampere sampai 65 ampere. Kenaikan tertinggi tegangan ultimate terjadi pada 60 ampere sebesar $45,14 \mathrm{Kgf} / \mathrm{mm}^{2}$, jika dibandingkan dengan material dasar untuk plat baja karbon rendah sebesar tegangan ultimate mengalami kenaikan sebesar 9,32\%, jika dibandingkan dengan bahan stailess steel tegangan ultimate mengalami kenaikan sebesar $23,53 \%$ dan jika dibandingkan dengan bahan filler mengalami penurunan sebesar10,03\%. Disini dapat diketahui bahwa tegangan ultimate lasan akan berada diatas tegangan ultimate plat baja karbon rendah dan tegangan ultimate plat stainless steel 


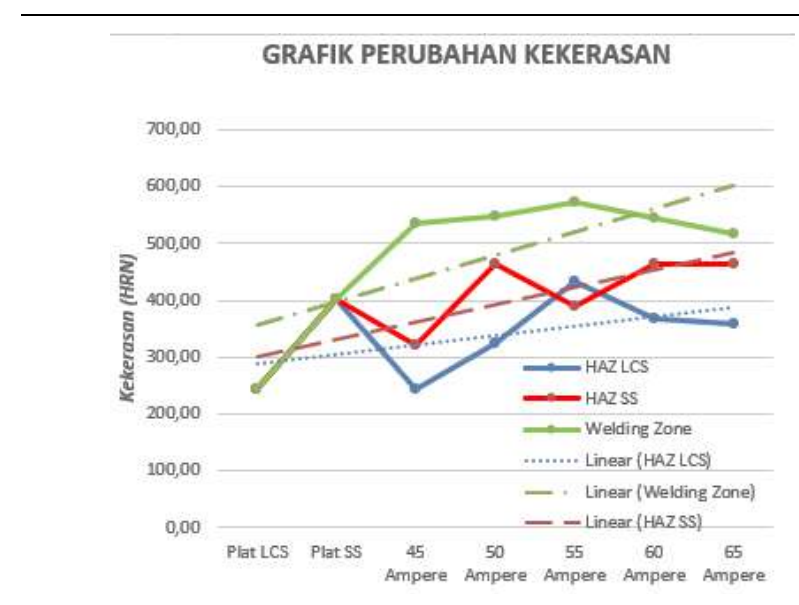

Gambar 4.6 Grafik perubahan kekerasan pada HAZ dan Lasan

Ditinjau terhadap perubahan kekerasan pada daerah HAZ plat baja karbon rendah, gambar 4.6 menunjukkan terjadinya trend kenaikan kekerasan dari perubahan pengaturan ampere las pada pengelasan Gas Tungsten Arc Welding (GTAW) dari 45 ampere sampai 65 ampere. Trend kenaikan tertinggi, kekerasan daerah HAZ plat baja karbon rendah terjadi pada penggunaan 55 ampere sebesar 431,65 $\mathrm{BHN}$, sedangkan jika dibandingkan dengan material dasar untuk plat baja karbon rendah sebesar $77,19 \%$.

Ditinjau terhadap perubahan kekerasan pada daerah HAZ plat stainlees steel, gambar 4.6 menunjukkan terjadinya trend kenaikan kekerasan dari perubahan pengaturan ampere las pada pengelasan Gas Tungsten Arc Welding (GTAW) dari 45 ampere sampai 65 ampere. Trend kenaikan tertinggi, kekerasan daerah HAZ plat stainless steel terjadi pada penggunaan 60 ampere sebesar 465,07 BHN, jika dibandingkan dengan material dasar stailess steel mengalami kenaikan sebesar $15,55, \%$.

Ditinjau terhadap perubahan kekerasan pada daerah lasan, gambar 4.6 menunjukkan terjadinya trend kenaikan kekerasan dari perubahan pengaturan ampere las pada pengelasan Gas Tungsten Arc Welding (GTAW) dari 45 ampere sampai 65 ampere. Nilai tertinggi, kekerasan lasan terjadi pada penggunaan 55 ampere sebesar 571,07 BHN, nilai terendah kekerasan pada penggunaan 65 ampere sebesar 516,81, jika dibandingkan dengan material dasar plat baja karbon rendah mengalami kenaikan sebesar 134,43 \%, jika dibandingkan dengan material dasar stailess steel mengalami kenaikan sebesar $41,89 \%$.

Ditinjau dari sisi bahan plat baja karbon rendah, tampak bahwa pada daerah pusat lasan (Welding Zone) terbentuk fasa $\alpha$ dan $\gamma$. Pada daerah terpengaruh panas plat baja karbon rendah (HAZLCS), terdapat tiga fasa yaitu fasa $\alpha, \alpha$, dan $\gamma$ dan pada daerah logam dasar (BM) terbentuk fasa $\gamma$. Hal ini mengindikasikan bahwa bahwa fasa $\mathrm{\gamma}$ masih tampak dominan pada semua daerah (WZ, HAZLCS dan BMLCS) akibat pemanasan dan pendinginan secara alami pada suhu kamar. Sedangkan pada sisi plat stainless steel, fasa $\alpha$ tampak pada semua daerah (WZ, HAZSS, dan BMSS). Hal ini mengindikasikan bahwa austenit tetap stabil meskipun terjadi pemanasan.

\section{DAfTAR Pustaka}

[1] Herman W Pollack,1991, Material Science and Metalurgy, $4^{\text {th }}$ edition, Reston Publishing Company, Inc, Reston Virginia.
[2] A Simplified explanation of welding polarity, http://stickweld.com/basic-information, diakses 19 Juni 2012.

[3] Andrewd Althouse, Artek Turnquist William A Bowdicth Modern Welding, The Good Heart Willcox Co. Inc, 1976

[4] Maman Suratman,S.Pd, Teknik Mengelas, Pustaka Grafika, Bandung, 2001

[5] Musaikan, Ir, Teknik Las, FTI Jurusan Teknik Mesin ITS, Surabaya, 1989

[6] https://en.wikipedia.org/wiki/Bimetal

[7] alatuji.com/article/detail/3/what-is-hardness-test-uji-kekerasan

[8] http://riset.unisma.ac.id/index.php/jts/article/view/705/6 93

[9] http://www.kobelco.co.jp/english/welding/events/files/2 015_KOBELCO_Specific.pdf

[10] https://hermanuloh79.blogspot.com/2015/08/caramemilih-jenis-pengelasan-untuk-konstruksi.html

[11] https://www.leonghuat.com/hardness.htm 